ВОРОНОВ Виктор Васильевич - доктор социологических наук, профессор, ведущий научный сотрудник Института социологии Федерального научно-исследовательского социологического центра Российской академии наук (117218, Россия, г. Москва, ул. Кржижановского, 24/35, корп. 5; viktor.voronov@du.lv)

\title{
МОДЕЛИРОВАНИЕ МЕЖЭТНИЧЕСКИХ ОТНОШЕНИЙ В РОССИЙСКИХ РЕГИОНАХ
}

\begin{abstract}
Аннотация. В статье на основе разработки этноэкономических моделей рассмотрены особенности развития межэтнических отношений в обследуемых регионах (Краснодарский край, Нижегородская и Тюменская обл.) в контексте общероссийской национальной и экономической безопасности. Автор приходит к выводу, что в основе гармоничных межэтнических отношений в стране и регионах может лежать формирование общей российской идентичности как единства многообразия этнических идентичностей народов России на цивилизационной базе русской нации - русского социокультурного типа.
\end{abstract}

Ключевые слова: диаспоры и землячества, мигранты, регион, этноэкономические модели

Введение. Под социальной моделью в статье понимается идеальный образец какого-либо социального объекта, процесса, воспроизводящего в символической форме его основные типические черты. Отсюда социальное моделирование - получение нового знания об изучаемом социальном объекте посредством сопоставления его с изученными модельными социальными объектами. Наиболее полно познавательные возможности социального моделирования, несмотря на трудности его квантификации, проявляются при рассмотрении его как метода системного исследования. Например, при анализе участия диаспор во внутренней политике современного государства ученые выделяют несколько этнополитических моделей такого участия: «лояльное участие» (этнополитический плюрализм русских в Киргизии, Молдавии), «лояльное поведение» (этнокультурное поведение русских в Азербайджане, Грузии), «протестное поведение» (этнополитическое отчуждение русских в Латвии, Эстонии) [Российская диаспора... 2011: 45-51]. С позиции этнической конфликтологии исследователи выделяют модель «монополизации шансов» [Дмитриев, Жуков, Пядухов 2009: 234-235]. Если мы будем рассматривать межэтнические отношения в России или в других странах с системных позиций, то этнические модели взаимодействия диаспор и землячеств с местным населением в обследуемых регионах имеют в своей основе экономические особенности той или иной хозяйственной практики региональных субъектов. Например, в странах ЕС наиболее известна этномодель мультикультурализма, а в США - «плавильного котла». В основе формирования этих моделей (проживание в границах одного государства различных этноконфессиональных групп, сохраняющих свою идентичность) - две причины, обусловленные логикой рынка. Первая, политико-правовая причина - унификация полиэтнического населения для того, чтобы оно могло эффективно функционировать в капиталистической системе как общегражданский объект эксплуатации. Вторая, экономическая причина - снижение государственных затрат на необходимость интеграции прибывающих этнических групп (внешних мигрантов).

В статье мы рассматриваем два типа некоренных этнических групп в российских регионах. Первый тип - представители этнических групп, проживающих вне страны своего происхождения, даже если ранее (до 1991 г.) она входила в состав Советского Союза. Назовем эти группы диаспорами. Такие группы неоднородны по социокультурному составу и включают как давно интегрированные 
слои, так и сравнительно недавно приехавших внешних мигрантов (трудовые мигранты, беженцы и др.). Второй тип - представители этнических групп, имеющие общность происхождения из другого российского региона. Назовем их землячествами (внутренние мигранты). В структуре населения большинства российских регионов, как правило, представлены оба типа этнических групп и их представителей. В России за не всегда позитивными отношениями между новыми диаспорно-земляческими сообществами (мигрантами) и местным сообществом в регионах стоит конфликт между отдельно сохраняющимися традиционными общинно-трудовыми отношениями и современными рыночными отношениями, определяющими процесс распада прежних форм организации жизни.

Методы исследования. В исследовании использованы количественные и качественные методы: данные государственной переписи (2002, 2010 гг.) населения по регионам, данные статистики, вторичных социологических исследований, а также глубинные интервью экспертов в 2015-2016 гг. $(N=134)$ - представителей референтных групп («власть», «наука», «этносы», СМИ) в 3 пилотных регионах: Западно-Сибирском (Тюменская обл. с автономными округами), Приволжском (Нижегородская обл.), Южном (Краснодарский край с Республикой Адыгея). Отбор экспертов осуществлялся с целью охвата уровней властей региона и распределения их компетенций, ученых, занимающихся данной проблематикой, представителей наиболее крупных диаспор и землячеств, а также отдельных представителей СМИ. Глубинные интервью проводились с представителями азербайджанской, армянской, грузинской, казахской, киргизской, курдской, украинской, таджикской и узбекской диаспор, а также представителями адыгейского, татарского, дагестанского, чеченского, чувашского землячеств в регионах.

Особенности этнохозяйственных типов экономической деятельности. Этнохозяйственный тип экономической деятельности различается у разных народов России и обусловлен как конфессиональным влиянием на социально-экономические и социокультурные установки, так и природно-климатическими условиями жизнедеятельности. У отечественных ученых имеются плодотворные исследования на эту тему. В исследованиях В.В. Радаева, И.М. Кузнецова и В.И. Мукомеля, А.В. Лайши и других авторов поднимаются общие вопросы формирования и развития этнической экономики, появления особых «этнических ниш» в российском предпринимательстве [Радаев 1993; Кузнецов, Мукомель 2007; Лайша 2012]. Конфликтогенный потенциал этнического предпринимательства исследуют Г.С. Денисова, В.П. Уланов [Денисова, Уланов 2003] и другие авторы. Работы Л.В. Милова и других авторов рассматривают особенности предпринимательской активности отдельных этносов, проживающих на территории России [Милов 2001].

В соответствии с полученными результатами можно выделить:

- производственно-государственный тип этнохозяйственной деятельности русского народа как взаимосвязанную реализацию промышленного и сельского труда из-за минимального объема совокупного прибавочного продукта, обусловленного природно-климатическими условиями и значительными транспортными издержками при реализации товаров;

- торгово-посреднический и земледельческий тип этнохозяйственной деятельности народов Средней Азии (казахов, киргизов, таджиков, узбеков);

- торгово-посреднический и сельско-животноводческий тип этнохозяйственной деятельности народов Северного Кавказа (дагестанцев, ингушей, осетин, кабардинцев, чеченцев).

Как отмечают отдельные авторы, «индустрия для русских в России является 
таким же отличительным признаком, как овцеводство - для горцев Дагестана или сфера автосервиса, гостиничного бизнеса - для армян» [Денисова, Уланов 2003: 218]. Этноэлиты на постсоветском пространстве свои привилегии, престиж и власть реализуют в основном не в сфере производственных ресурсов, а в сфере перераспределения. Поэтому функционирование государственного управления (подбор и ротация кадров) в регионах, где сильны позиции этноэлит, осуществляется по этническому, а не по профессиональному основанию, что снижает квалификацию работников и нейтрализует попытки модернизации госаппарата, органов правопорядка и социальной сферы в общегосударственных интересах.

По верному замечанию исследователей, «экономические институты в сфере промышленного производства и в значительной мере - в сфере сельского хозяйства оказались не принятыми и не интегрированными в культуру автохтонных народов Кавказа. Уже разрушенные к настоящему времени, они фактически обречены на стирание в системе социальных взаимодействий» [Денисова, Уланов 2003: 257].

Рыночные преобразования на постсоветском пространстве привели к обесцениванию деятельности в реальном (особенно индустриальном) секторе экономики и резко сузили структурные возможности рынка труда. Это наиболее негативно отразилось на русском народе. Суть такого процесса деиндустриализации с этнических позиций такова: она выдавливает русских с национальных окраин бывшего союзного государства и с российского Северного Кавказа. Индустриальный сектор на постсоветском пространстве сжимается за счет расширения сферы торговли и услуг. В национальных автономиях и республиках идет земельный передел собственности по этническому, а не социальному принципу: земля закрепляется в основном за автохтонными народами. При этом, например, на Северном Кавказе практически исчезла обрабатывающая промышленность, где были заняты квалифицированные рабочие и инженерные кадры - в основном русские работники. Экономика там свелась к тремчетырем составляющим: 1) сельское хозяйство с производством для переработки его продукции, 2) транспорт, 3) топливно-энергетический и 4) рекреационно-туристический комплексы [Денисова, Уланов 2003: 173-175]. Поэтому на первое место в условиях рынка выдвигаются преимущественно не социальные качества человека (трудовая активность, цели жизни и т.д.), а этнические (конфигурация национального характера, обычаи, традиции и т.д.).

У российского государства исторически сформирована очень развитая хозяйственно-экономическая функция, ведь «государственная машина» была вынуждена форсировать объективный процесс углубления общественного разделения труда в крестьянской стране. Отсюда необычайная активность государства в области так называемых всеобщих условий производства: создание инфраструктуры (дороги, каналы, города-крепости обширного приграничья), возведение заводов, фабрик, верфей, портовых сооружений и обеспечение всего этого рабочей силой, профессиональными кадрами. В пространственных и природно-климатических условиях России функционирование многих отраслей экономики без важнейшей роли государственного сектора, элиминировавшего безжалостные механизмы стоимостных отношений, было невозможно на всем протяжении российской истории [Милов 2001: 151].

Этноэкономические модели взаимодействия диаспор и землячеств с местным сообществом. В российской социально-экономической и социокультурной ситуации можно выделить основы этноэкономических моделей взаимодействия диаспор и землячеств с местным сообществом, опираясь на следующие критерии: 
- цели экономического участия в указанном взаимодействии (получение выгоды, участие в общем деле, др.);

- форма такого участия (конвенциональная или неконвенциональная, т.е. девиантная форма экономического поведения представителей диаспор и землячеств);

- стратегии власти в отношении диаспор и землячеств (ассимиляция, обособление, интеграция).

На основании указанных критериев в условиях современной России можно выделить несколько таких этноэкономических моделей: рационально и иррационально рыночные, а также нерыночную трудовую. Назовем и опишем три основные, по нашему мнению, модели. Анализируемые модели в современном российском обществе в чистом виде на практике вряд ли встречаются: обычно они сочетаются друг с другом при ведущей роли определенной стратегии адаптации к существующим социально-экономическим условиям, принимая характер сложных комплексных трансформаций коммуникационных связей и поведения различных этнических групп.

1. Этноэкономическая модель рыночных отношений и поведения, т.е. модель выгоды и частного интереса, рыночная модель. Коррелирует с инструментальным этнокультурным подходом, где этническая принадлежность используется как эффективный ресурс социальной мобильности и роста социального статуса в принимающем обществе. Характерна для представителей диаспор из Средней Азии, азербайджанской и армянской диаспор.

В структуру этноэкономической модели рыночных отношений и поведения входят:

- приоритет частного бизнеса в хозяйственной деятельности любого уровня, для которого государство лишь создает условия для работы;

- селективная минимизация затрат на иноэтничную наемную рабочую силу (внешних мигрантов);

- свободное перемещение наемной рабочей силы с учетом общих правовых норм;

- индивидуальная минимизация издержек и максимизация выгод представителями этнических групп в своей социально-экономической деятельности.

2. Этноэкономическая модель конфликтных отношений и поведения, т.е. клановая модель. Коррелирует с примордиалистским этнокультурным подходом, устанавливающим приоритет лояльности своей этнической группе по сравнению с лояльностью принимающему обществу. Характерна для представителей землячеств Северного Кавказа: дагестанцев, ингушей, чеченцев.

В структуру этноэкономической модели конфликтных отношений и поведения (клановой модели) входят:

- наличие этнических групп с теневой кадровой иерархией, сетью региональных посредников (район-город-область);

- устойчивые практики взаимодействия работников как представителей разных этнических групп и их работодателей;

- анализ спроса на региональном рынке труда разных категорий работников-мигрантов (внутренних, внешних) и анализ предложения на их этнической родине или стране исхода;

- наличие отработанного механизма получения и распределения доходов от монополистической деятельности определенной этнической группы в регионе;

- наличие структур силового прикрытия коммерческой деятельности представителей этнических групп и применение санкций к нарушителям внутри данного сообщества; 
- покровительство представителям этнических групп в местных органах власти и деловых кругах региона на возмездной основе.

3. Этноэкономическая модель солидарных отношений и поведения, т.е. модель общего дела, коллективистская, солидарная модель. Коррелирует с конструктивистским этнокультурным подходом, где культурные стандарты этнических групп постепенно интегрируются с нормами и символами принимающего общества. Характерна для представителей диаспор из Белоруссии, Украины, Казахстана, представителей землячеств адыгов, башкир, татар.

В структуру этноэкономической модели солидарных отношений и поведения с нормативных позиций входят:

- согласование интересов (от общих к частным) субъектов хозяйственной деятельности в стране и регионах;

- системное развитие всех секторов экономики;

- выравнивание социально-экономических условий развития регионов для роста качества жизни всех их жителей;

- реализация принципа социальной справедливости, обеспечение порядка и равенства всех перед законом;

- дифференцированная поддержка диаспор и землячеств в регионах в интересах устойчивого развития последних.

При этом надо учитывать особенности интеграции разных этнических групп в региональных сообществах из-за различия и специфики региональных проблем. По верному замечанию отдельных авторов, важной задачей является формирование региональных моделей национальной политики, и такие модели должны учитывать объективные процессы, идущие в локальных межэтнических сообществах [Попков 2017: 126].

Теоретические и практические исследования, проведенные в обследуемых регионах, показали, что устойчивое (неконфликтное) взаимодействие диаспор и землячеств с местным населением происходит в условиях, когда большинство местного населения представлено славянским народом одной культуры и истории: русскими, украинцами, белорусами и комплиментарными к нему народами, долгое время живущими вместе: адыгами, азербайджанцами, армянами, башкирами, казахами, молдаванами, татарами и др. Такое взаимодействие предполагает два взаимосвязанных элемента: социокультурные отношения, характерные для традиционного трудового общества, и социально-экономические отношения, характерные для нерыночной экономики.

Наоборот, в тех регионах, где русские оказываются в меньшинстве среди местного населения (14 регионов, среди которых наиболее проблемные северокавказские), где нарушено воспроизводство российских центральных институтов русского социокультурного типа (символы общероссийской государственности, крупные коллективные формы хозяйствования, идеология коллективизма и сотрудничества и др.) идет резкое снижение статусных позиций русской части населения в регионе и повышается конфликтогенность межэтнических отношений.

В настоящее время в регионах заметное распространение во взаимоотношениях местного населения с представителями диаспорно-земляческих сообществ получает этничность как инструмент в двух аспектах: это социокультурный инструментализм (внимание к мобилизации этнических и конфессиональных чувств того или иного народа) и экономический инструментализм (внимание к разным формам адаптации в хозяйственной деятельности и на рынке труда членов различных этнических групп). Этническая группа рассматривается здесь как группа людей общей идентичности (осознающие свою принадлежность к данной группе), общей истории и культурной традиции, 
общего языка. Исследователи различают внешние факторы адаптации представителей этнических групп: культурную дистанцию между мигрантами и принимающим сообществом; институциональные факторы (развитость институтов социальной поддержки мигрантов); положение этнических групп в социальной структуре общества, а также внутренние факторы (характеризующие самих мигрантов): культурную компетентность мигранта (образованность, информированность, опыт); аккультурационную мотивацию (ассимиляция, интеграция, обособление и др.); силу социальных связей в группах мигрантов (развитость этнических коммуникаций).

Важным признаком этнической группы выступает идентификация ее членов, которые осознают различия (происхождение, традиции, конфессия и т.п.) между своим сообществом (диаспора/землячество) и местным.

В обследуемых регионах, где преобладает русское этническое большинство, в целом реализуется умеренно-позитивный процесс интеграции, взаимоотношений «старожильческих» и новых диаспорных и земляческих групп с местным сообществом. Также еще существует возможность реальной и системной интеграции стран СНГ по совместной жизнедеятельности их народов. На рыночных условиях такая интеграция вряд ли возможна, наоборот, потребуется жесткая визовая политика, вызванная проблемной по своим социально-экономическим последствиям этнической миграцией. В этой связи для обеспечения социально-экономической и социокультурной безопасности страны и ее регионов необходима разработка системы региональных пороговых показателей (индикаторов, индексов) процесса интеграции иноэтничных групп.

В заключение можно утверждать, что устойчивые межэтнические отношения при взаимодействии диаспор и землячеств с местным сообществом, способствующие интеграции полиэтничного населения, возможны лишь при реализации этноэкономической модели солидарных отношений и поведения (модели совместного развития). Однако без смены либерально-рыночной экономической системы на систему смешанной, социально и национально ориентированной экономики консолидация общероссийского пространства вряд ли возможна. К ее основным параметрам следует отнести:

- жесткий хозяйственный протекционизм в интересах развития страны с последующим выходом из ВТО;

- работу финансовой системы в интересах производительного сектора;

- высокие налоги на личные сверхдоходы и пониженные - на производительную деятельность;

- полный национальный контроль над природно-ресурсным комплексом, вплоть до национализации;

- разнообразие хозяйственных укладов и форм собственности, где малый и средний бизнес могут быть частными, но крупный бизнес - только общественным (государственным), и др.

Существующая социально-экономическая система способна воспроизводить лишь этноэкономические модели рыночных отношений и поведения и конфликтных отношений и поведения, которые не дают простора интеграционным процессам развития межэтнических отношений диаспор/землячеств с местным сообществом. Вместе с тем есть надежда на появление необходимых социально-экономических факторов и возможностей пространственной и межэтнической консолидации России. Эта надежда связана с разработкой в 2017 г. государственной Стратегии экономической безопасности Российской 
Федерации на период до 2030 года ${ }^{1}$, которая может выступить обнадеживающим фактором для перехода экономики к мобилизационной модели развития страны и ее регионов. По нашему мнению, в Стратегии основным фактором выступает «общее дело», понимаемое в смысле социальных технологий продуктивной кооперативной деятельности, которые выработала российская цивилизация за века своей истории. В этих условиях на государственном уровне может появиться возможность формирования этноэкономической модели солидарных отношений и поведения (модели совместного развития) диаспор и землячеств с местным сообществом. Это заявка на уход от статуса колониального придатка Запада и попытка возвращения российского государства после четвертьвекового отчуждения к своему государствообразующему субъекту - к русскому народу. Социально-экономические и социокультурные коды русского народа (самодостаточность, мастеровитость, коллективизм, радушие, уживчивость, доброта) способны формировать и воспроизводить устойчивые межэтнические и межконфессиональные отношения на принципах сплоченности, социальной справедливости и обеспечения равенства всех перед законом. В основе гармоничных межэтнических отношений в стране и регионах может быть лишь формирование общей российской идентичности как единства многообразия этнических идентичностей народов России на цивилизационной базе русской нации - русского социокультурного типа.

\section{Список литературы}

Денисова Г.С., Уланов В.П. 2003. Русские на Северном Кавказе: анализ трансформации социокультурного статуса. Ростов н/Д: Изд-во РГПУ. 352 с.

Дмитриев А.В., Жуков В.И., Пядухов Г.А. 2009. Миграция: конфликт, безопасность, сотрудничество. М.: Изд-во РГСУ. 354 с.

Кузнецов И.М., Мукомель В.И. 2007. Формирование этнических ниш в российской экономике: история вопроса. - Неприкосновенный запас: дебаты о политике и культуре. № 1. С. 175-184.

Лайша А.В. 2012. Этническое предпринимательство в современной России и перспективы его развития. - Философские науки. № 4. С. 121-126.

Милов Л.В. 2001. Великорусский пахарь и особенности российского исторического процесса. М.: РОССПЭН. 576 с.

Попков Ю.В. 2017. Государственная национальная политика как фактор межэтнической интеграции российского общества. - Siberian Socium. T. 1. № 1. C. 114-131.

Радаев В.В. 1993.Этническое предпринимательство: мировой опыт и Россия. - Полис. Политические исследования. № 5. С. 79-87.

Российская диаспора как фактор укрепления национальных интересов России на постсоветском пространстве. 2011. М.: Институт диаспоры и интеграции (Институт стран СНГ). 148 с.

1 Указ Президента РФ от 13.05.2017 «О Стратегии экономической безопасности Российской Федерации на период до 2030 года». Доступ: http://www.garant.ru/products/ipo/prime/doc/71572608/ (проверено 10. 08. 2018). 
VORONOV Viktor Vasil'evich, Dr.Sci. (Soc.), Professor, Leading Researcher of the Sociological Institute - branch of the Federal Center of Theoretical and Applied Sociology, Russian Academy of Sciences (bld. 5, 24/35 Krzhizhanovskogo St, Moscow, Russia, 117218; viktor.voronov@du.lv)

\title{
MODELLING OF INTERETHNIC RELATIONS IN RUSSIAN REGIONS
}

Abstract. On the base of generation of ethno-economic models, the article considers features of the development of the inter-ethnic relations in the regions under survey (Krasnodar Region, Nizhny Novgorod and Tyumen Regions) in the context of the all-Russian national and economic security. The author concludes that the formation of a common Russian identity as the unity of the diverse ethnic identities of the peoples of Russia on the base of civilization of the Russian nation - Russian socio-cultural type could be basic for harmonious interethnic relations in the country and regions.

Keywords: diasporas and communities, migrants, region, ethno-economic models

КЛИМЕНКО Людмила Владиславовна - доктор социологических наук, доцент; профессор Высшей школы бизнеса Южного федерального университета (344019, Россия, г. Ростов-на-Дону, ул. 23-я линия, 43; lucl@yandex.ru)

ПОСУХОВА Оксана Юрьевна - кандидат социологических наук, доцент; доцент Института социологии и регионоведения Южного федерального университета (344006, Россия, г. Ростов-наДону, ул. Пушкинская, 160; belloks@yandex.ru)

\section{ПРЕКАРИАТИЗАЦИЯ ТРУДА И ПРОТЕСТНЫЕ НАСТРОЕНИЯ СОЦИАЛЬНО ОРИЕНТИРОВАННЫХ ПРОФЕССИОНАЛЬНЫХ ГРУПП В РОССИЙСКОМ ОБЩЕСТВЕ}

\begin{abstract}
Аннотация. В статье представлены результаты опроса учителей и врачей бюджетных школ и больниц российских мегаполисов (г. Москвы, г. Ростова-на-Дону и г. Казани) в 2017-2018 гг. В статье рассматривается восприятие представителями социально ориентированных профессий своего социального и экономического положения; оценка степени прекариатизации их труда; уровень выраженности протестных настроений. Результаты исследования фиксируют выраженные риски прекариатизации городских учителей и врачей, связанные с нестабильностью их работы, повышением трудовой нагрузки без соответствующего роста зарплаты. Однако уровень протестных настроений представителей социально ориентированных профессий достаточно низок.
\end{abstract}

Ключевые слова: социально ориентированные профессиональные группы, прекариатизация социально-трудовых отношений, школьные учителя, врачи, мегаполис, трудовые права

Введение. В процессах интеграции общества и обеспечения социального порядка через воспроизводство и трансляцию нормативных ценностных установок и моделей поведения большую роль играет профессиональная деятельность социально ориентированных профессий (учителей и врачей) [Клименко, Посухова 2017а]. Не вызывает сомнения социетальная роль учительства, которое осуществляет знаниевую и ценностную социализацию молодежи и тем самым способствует поддержанию целостности общества. Деятельность врачей также сопряжена с непосредственным контактом с гражданами и нацелена на сохранение жизни человека и улучшение ее качества путем оказания медицин- 